\title{
Chapter 3 \\ Student and/or Teacher Valuing \\ in Mathematics Classrooms: Where Are \\ We Now, and Where Should We Go?
}

\author{
Monica E. Carr
}

\begin{abstract}
A seminal literature review of values in mathematics education was conducted at the turn of the century, and at that time revealed a paucity of research in this area (Bishop et al. in Values in mathematics teaching: The hidden persuaders? Dordrecht, The Netherlands: Kluwer Academic Publishers, 2003). Bishop and colleagues noted that a change in the values being taught is implicit in any recommendation for changing teaching, and argued that any significant development in mathematics education probably implies a change in values. Research in values in mathematics education remains a high priority today as STEM participation and achievement around the globe continues to encounter many challenges. This chapter presents an updated systematic literature review of values in mathematics classrooms with a view to identifying what has been achieved more recently in this field. Using a systematic search of peer-reviewed publications, some 299 abstracts met key term search criteria. Following an examination of the abstracts, a final data set of 34 studies were retained for further review and analysis. Research methodology, geographic location, stakeholder — teacher or student—valuing, age, grade level, gender, and a summary of original main conclusions were reported for each of the relevant studies. Results were synthesized across the data set to describe where the body of research is at currently.
\end{abstract}

Keywords Literature review $\cdot$ Mathematics $\cdot$ Students $\cdot$ Teachers $\cdot$ Values

\subsection{Introduction}

The study of values spans a broad multi-disciplinary terrain, with different disciplines pursuing the central concept of values from unique orientations. In the seminal literature on values in anthropology, Kluckhohn and Strodtbeck (1961) wrote that values can be conceptualized as being able to answer basic existential questions and to help

M. E. Carr ( $\varangle)$

Melbourne Graduate School of Education, The University of Melbourne, Melbourne,

VIC, Australia

e-mail: mcarr.phd@gmail.com

(C) The Author(s) 2019

P. Clarkson et al. (eds.), Values and Valuing in Mathematics Education,

ICME-13 Monographs, https://doi.org/10.1007/978-3-030-16892-6_3 
provide meaning in people's lives. To social scientists, values are viewed as a means to help ease conflicts between collective and individual interests. Through this lens, values can be conceptualized as serving an important function in which individuals can work together to attain goals that are ascribed to by the collective group (Parsons and Shils 1951).

Although many definitions of values abound in the broader literature, unique meaning and role of values and valuing have been defined by the mathematics teaching and learning community. In his seminal discussion on culture and values in mathematics, Bishop (1988a) introduced six fundamental activities that he argued are universal, necessary and sufficient for the development of mathematic knowledge: counting, locating, measuring, designing, playing, and explaining. Subsequently Bishop (1988b) envisaged values as a variable of affect, and went on to describe six values that underpin the widely utilised notion of Western mathematics: rationalism and objectism; mystery and openness; control and progress.

At the start of the 21 st Century the first literature review of values in mathematics education was conducted by Bishop et al. (2003). Reporting a dearth of literature, Bishop and colleagues noted that most empirical research was conducted within the five years prior to their review. In particular, the ARC Project Values in Mathematics Project_-VAMP (1999-2002) was awarded to Bishop and Clarkson, whilst around the same time a parallel project led by Lin and colleagues was conducted in Tawain. Bishop and Clarkson reported that some studies covered in their literature analysed the values portrayed by text materials used in teaching mathematics. Other studies focused on mathematics classroom teachers, and on values-related activities within the classroom.

Bishop and colleagues (2003) attributed two main reasons for the paucity of research at the intersection of mathematics education and the values area. Firstly, the universalism of mathematics, in which mathematical concepts transcend language or geographic location together with the universal applicability of mathematical ideas, fosters the belief that mathematics is culture-free and therefore value-free knowledge. Bishop and colleagues explained that this universalism is one of the prime values underlying the "western" notion of mathematics that has gained pre-eminence in all parts of the world. Secondly, Bishop and colleagues described the long-held belief that mathematics teachers do not need to take social aspects of mathematics education into account in their teaching, which has resulted in the technique-oriented curriculum in which skill teaching and learning are the central focus. Bishop and colleagues reported that any significant development in mathematics education probably requires challenging these established beliefs. Accordingly, Bishop and colleagues argued the importance of taking values into consideration in future mathematics education research emphasizing that a change in the values being taught is implicit in any recommendation for changing teaching.

Initially, Seah and Bishop (2001) defined values in mathematics education as:

... One's internalisation, cognitisation, and decontextualisation of affect variables (such as beliefs and attitudes) in one's socio-cultural context. They are inculcated through the nature of mathematics and through one's experience in one's socio-cultural environment and in the mathematics classroom. These values form part of one's ongoing developing personal 
value system, which equips one with a pair of cognitive and affective lenses to shape and modify ones way of perceiving and interpreting the world, and to guide ones choice of course of action. They also influence the development of one's other beliefs and ones needs in mathematics education and in life (p. 444).

Definitions of values in mathematics education have continually evolved since that time, with Seah (2018) most recently writing that:

... valuing refers to an individual's embrace of convictions which are considered to be of importance and worth. It provides the individual with the will and grit to maintain any 'I want to' mindset in the learning and teaching of mathematics. In the process, this conative variable shapes the manner in which the individual's reasoning, emotions and actions relating to mathematics pedagogy develop and establish (Seah 2018, p. 575).

In earlier literature, values were viewed by Bishop as an affective variable. An important distinction between this and the current definition proposed by Seah is that values are viewed as a conative variable. In light of global diversity driven by modern migratory trends, in which students, teachers, and parents are submersed in new cultures, an "individual's embrace of convictions" is arguably of particular significance.

Science, Technology, Engineering, and Mathematics (STEM) form the backbone of our current global economies, with sectors such as education, engineering, food production, health care, infrastructure, manufacturing, research and development, supply chain, and transportation relying heavily on a STEM skilled workforce. Arguably, achievement in mathematics is vital to the adequate preparation of students to meet the technical needs of jobs of the future. However, falling rates of participation and achievement in STEM subjects has been widely acknowledged in Australia (Timms et al. 2018). Seah (2018) has highlighted the significant, though often overlooked, role of values in supporting the cognitive development and affective state of mathematics students. Accordingly, research in values in mathematics education remains a high priority. Common to any exploration of values, some form of measurement of the values held is necessary. Value measurement requires a questioning process through which themes are explored such as: what values are held by individuals?; how are various values prioritized?; and what variations or similarities in values may exist amongst cultures? are explored. In response to these challenges, and shaped by these value measuring aims, The Third Wave Project led by Seah commenced in 2009. At the time of this writing nearly all active researchers in the field of values in mathematics education have been invited to participate.

Primary sources of literature provide first-hand information on studies and includes detailed descriptions of the studies' methodology, data, analysis, results and findings. Although published in a variety of sources including journal articles, book chapters, dissertations, or conference papers, a review including all primary literature sources is beyond the scope of this chapter. As such, this current review has been restricted to peer-reviewed journal articles that arguably reflect the most current and complete studies that have undergone a rigorous review process. Presenting an updated systematic literature review of values in mathematics education, this study aims to provide a map of the empirical research conducted to date, and to 
assist future researchers shape their exploration in values and valuing in mathematics education. The following research questions were developed:

i. Where has research been conducted?

ii. Which stakeholders are represented in the research?

iii. What is known about the development of values?

iv. How consistent are the findings reported in the studies?

\subsection{Systematic Search Procedure}

The What Works Clearinghouse (WWC) Procedures Handbook Version 4.0 has been developed by the U.S. Department of Education's Institute of Education Science (IES) to facilitate a systematic literature review process that uses consistent, objective, and transparent standards and procedures (WWC Procedures Handbook V4.0, 2017). The WWC review process comprises five steps: developing the review protocol to define the parameters for the research to be included in the review; identification of relevant literature; screening studies; reviewing studies; reporting on findings. While values research in mathematics education is a relatively young field, the WWC systematic review framework was adopted for this current chapter to provide a replicable procedure for future researchers working in this field.

Studies were located by conducting a systematic search of peer-reviewed literature published between January, 2003 and March, 2018. Both the PsycINFO and ERIC databases were queried using the search terms math* AND valu*. The abstract of each article was examined to determine whether an article was likely to meet inclusion criteria for further review, and a review of the full article was conducted when further clarification was necessary. Inclusion criteria required that:

1. The study reported on mathematics "teaching" or "learning" for students studying at primary or secondary levels

2. The study reported empirical data that may have been gathered from: classroom work; project work; homework; assessments; classroom observations; field notes

3. The study reported on either teacher, student, or parent/guardian valuing

4. The study investigated values alone, or in conjunction with other components of mathematics education such as test anxiety, personality, and/or beliefs

5. The full article was published in English in a peer-reviewed journal.

The psycINFO database search identified 109 abstracts that met search term criteria. Following examination of each abstract, 67 articles were retrieved for further clarification. Of the 52 studies that met the inclusion criteria (see 5 points above) for this review, 21 were published before 2003 and thus omitted from further review. Two journal articles - that is, Dede (2006) and Eklof (2007) — were unable to be located and were subsequently omitted from further review.

The ERIC database search identified 190 abstracts that met search term criteria. Following examination of each abstract, 16 articles were retrieved for further clarification to determine adherence to inclusion criteria as the abstract alone provided 
insufficient information about the study. Three studies from the USA, one study covering both the UK and Canada, one study from Malaysia, and one study from Africa studies did not include empirical data and thus were omitted from further review. One study from Taiwan provided data for science rather than mathematics, and was also omitted from further review. One study that explored values in Hawaii was unable to be located either in the university library or elsewhere (Furuto 2014), and was omitted from further review.

\subsection{Results and Discussion}

The search and study inclusion procedure identified 34 studies that reported on a variety of stakeholder perspectives as they relate to values and valuing in mathematics education. The Appendix provides a descriptive overview of each study included in the review. The number of annual publications were plotted in the line graph depicted in Fig. 3.1. The trend line indicates a positive growth in publication volume, reflecting the growing interest by researchers in this field.

\subsubsection{Where Has Research Been Conducted?}

Studies were conducted by 30 research teams, of which two studies are affiliated with the Third Wave Project (Dede 2013a, b). The studies presented in this review were conducted in 14 countries: Australia (1), Canada (3), Finland (1), Germany (12), Greece (2), Hong Kong (1), Israel (1), Norway (2), Singapore (1), South Africa (1), Sweden (1), Taiwan (2), Turkey (3), and USA (7), as depicted in Fig. 3.2. Of these, multiple-site study data was collected in Germany, Canada, and Israel (Boehnke 2005), and Greece and Turkey (Dede 2013a, b). One study analyzed data from 60 nations and presented meta-level findings with country specific findings not described individually (Fang et al. 2016).

Fig. 3.1 Frequency of publications

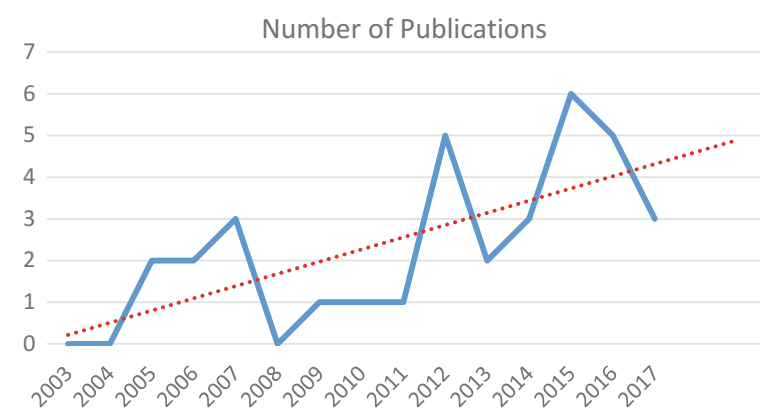




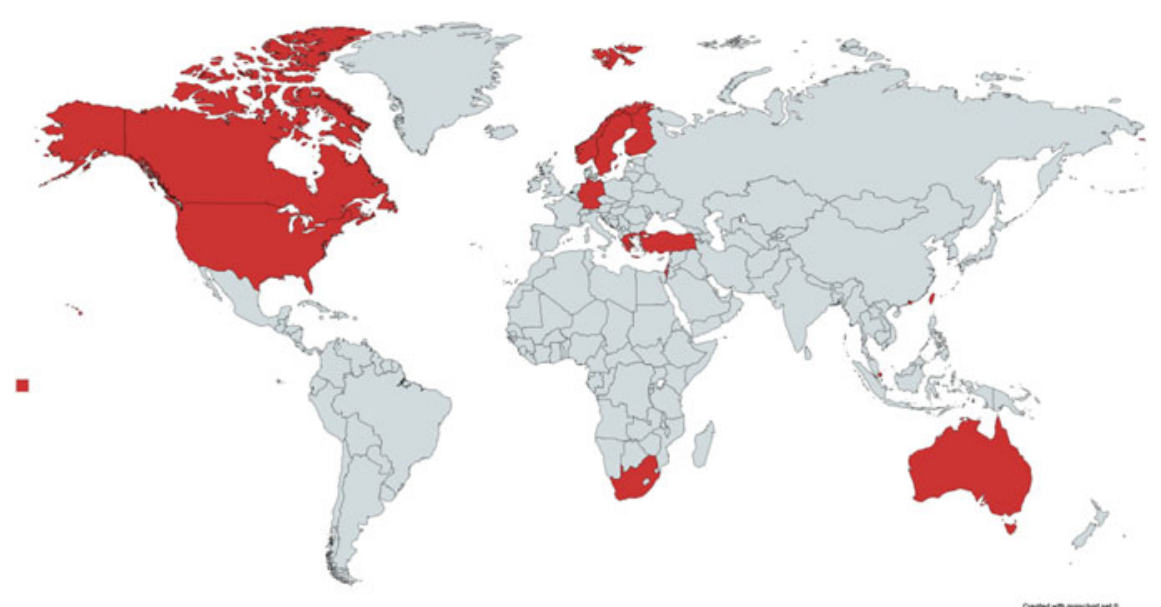

Fig. 3.2 Map of the countries that studies have been conducted in

\subsubsection{Which Stakeholders Are Represented in the Research?}

While studies primarily collected data directly from the students, teacher data (Chouinard et al. 2007; Dede 2013a, b; Diemer et al. 2016; Federici and Skaalvic 2014; Haara and Smith 2012; Leu 2005; Metallidou and Vlachou 2010; Peng and Nyroos 2012), parent perspectives (Gniewosz and Noack 2012; Chouinard et al. 2007), and peers (Bissell-Havran and Loken 2009) were occasionally included. A total of 152,500 student participants were included in the 34 studies.

Student participants ranged from 7.5 to 18 years. The majority of studies focused on students who have reached adolescence rather than students in their early years. Two articles reported on a longitudinal studies that tracked students from Grade 6 until Grade 12 (Wang 2012), and from Grade 3 until Grade 12 (Simpkins et al. 2006).

\subsubsection{What Is Known About the Development of Values?}

Factors that may influence the development of values was a common theme amongst the studies. In particular, student-perceived ability was frequently examined, noted in five studies (Gniewosz and Watt 2017; Viljarants et al. 2016; Diemer et al. 2016; Gaspard et al. 2015; Metallidou and Vlachou 2010). One study reported on the development of student values in mathematics as a function of maternal and paternal values in mathematics (Gniewosz and Noack 2012), one study reported on the supportive role of peers and students perceptions of their peers valuing in mathematics (BissellHavran and Loken 2009), and one study reported on the influence of mathematics classroom experiences over the development of students values (Wang 2012). One 
study examined the profile of a resilient learner who has succeeded in mathematics despite adversity, and described a female learner in which the language of classroom instruction was not spoken at home, who places a high value on mathematics (Frempong et al. 2016).

The utility of modelling activities compared to traditional problems solving and the subsequent impact of the development of student values was reported in two studies (Dorak 2012; Haara and Smith 2012). The role of values in relation to mathematics anxiety was explored in one study (Henschel and Roick 2017), in relation to the prediction of motivation and effort in mathematics was explored in five studies (Andersen and Cross 2014; Berland and Steingut 2016; Federici and Skaalvik 2014; Hsiang 2017; Penk and Schipolowski 2015) and more specifically in relation to effort in mathematics homework in one study (Trautwein et al. 2006).

One study examined self-regulated strategy use in elementary mathematics and specifically considered the role of student valuing in this context (Chatzistamatious et al. 2015). The authors reported that enjoyment and positive valuing of the importance of mathematics as a school subject are necessary for mastery goals to have a positive effect on students' use of self-regulated strategies in mathematics. Elsewhere, the relationship between self-concept and utility values in the prediction of educational outcomes, including persistence in mathematics, was reported in three studies (Guo et al. 2015; Andersen and Ward 2014; Fries et al. 2007). One study reported that the relationship between achievement value and academic achievement performance was not overly strong and suggest that achievement values may play an ambiguous role in generating high academic performance (Boehnke 2005).

\subsubsection{How Consistent Are the Findings Reported in the Studies?}

Gender was explored in five studies, with two studies describing gender differences (Henschel and Roick 2017; Gaspard et al. 2015) and three describing consistency in findings for both genders (Muis et al. 2015; Guo et al. 2015; Simpkins et al. 2006). One study specifically described omitting special needs students from their data (Penk and Schipolowski 2015), one study noted that $30 \%$ of the students had an Individualised Education Plan (IEP) (Muis et al. 2015), and one study included one general education class and one special education class (Peng and Nyroos 2012). Difference in values held by general education students when compared to students in special needs education was described in one study (Peng and Nyroos 2012). 


\subsection{Conclusion and Implications}

The aim of this study was to provide a mapping of the empirical research that has been conducted to date, and to use the research findings to inform the evolving definition of values in mathematics education. Findings from the data set as a whole suggest that the role of students' levels of motivation and effort are of prime importance to understanding student values in mathematics. Developing an understanding of how students perceptions of their mathematical abilities impact their valuing has been given almost equal attention in the research. The utility value of mathematics, and how this relates to student valuing has been frequently investigated. The most frequently represented countries in the data set are Germany and the USA.

Although the majority of studies included high school students, research conducted in lower grade levels has suggested students with higher cognitive ability and greater motivation hold high value beliefs in mathematics (Metallidou and Vlachou 2010), and that positive value beliefs are necessary for mastery goals to be effective (Chatzistamatiou et al. 2015).

Drawing upon the current findings, it appears that there is general agreement that suggests that values are a reflection of motivation and effort largely shaped by perceived ability. Additionally, the role of perceived utility appears central to the subsequent values held by the individual. When considered using the traditional theory of psychology, the classic partition of the mind is viewed in terms of three functions: cognition, emotion, and conation - the will or volitional component that drives an individual in his or her application to a given task. To date it appears that values researchers have explored cognition, and emotion largely operationalizing the investigations in terms of ability, achievement, self-concept, motivation and effort. Less is currently known about the role of conation in shaping values.

In contrast to frequent reports of the significance of positive valuing of high achievement in relation to favourable academic performance outcomes, the exploratory study conducted by Boehnke (2005) has highlighted a weak relationship. More specifically, Boehnke has explained that the impact of achievement values on performance is always indirect, elaborating that such valuing infact impact achievement related self-esteem. Boehnk demonstrated a two-field influence of achievement value on grades arguing both a positive and negative impact on achievement related self-esteem. While noting the line of research as exploratory, Boehnke has alerted educational researchers to the possibly ambiguous role achievement values play in the generation of high academic performance. Further, inconsistent findings are included in this data set regarding the role of gender differences in relation to values in mathematics.

To date little research investigating changes in values in mathematics teaching and learning has been conducted, either across time or as environmental changes attributed to migratory and immigration trends occurs. One large group study conducted in Taipei, Singapore, and America across both Grade 4 and Grade 8 reported that student values and competence beliefs decrease over time (Hsiang-Wei 2017). More specifically, we can understand this to mean that the less students like mathe- 
matics over time, the less they believe they are competent in this subject, and deduce that their positive valuing of mathematics as a subject decreases. Ongoing research conducted across time intervals, and in a variety of location appears highly warranted, to better identify patterns in changes in valuing and subsequently develop intervention strategies aimed to promote optimal outcomes in student mathematics achievement.

Immigration trends around the world has meant that many families are relocating to new countries. Research into whether existing values in mathematics education are retained, or new values developed is one important line of query. In particular, questions arise regarding whether opportunities in new environments are able to be accessed by newly arrived families, and do these new settings contribute to positive associations with studying mathematics.

The main data collection method utilized by these studies has been a self-report questionnaire instrument, of either student or other stakeholder measures. Few studies have included other data sources, such as classroom observations or interviews, and even fewer studies have included multiple stakeholder responses. Few longitudinal studies have been conducted (Muis et al. 2015; Simpkins et al. 2006). Further, there is a paucity of research that has adopted a pre- and post- assessment of valuing in conjunction with mathematics classroom teaching intervention, skill-building intervention, or home-work intervention. Future research that addresses these knowledge gaps appears highly warranted.

Countries around the world are encountering multi-culturism in new ways. With this comes new challenges to mathematics education, and arguably the field of values is increasingly pertinent to successful teaching and learning of mathematics. Many students face tremendous challenges before entering the mathematics classroom language barriers, ethnic or racial tension, economic hardship to name but a few. In these instances, it is increasingly important to address a variety of factors in the broader environment that may impact experiences inside the mathematics classroom. Values would be one of these factors, given that these are often shaped externally in the societies and communities in which the students operate, but espoused in the classrooms as the students negotiate on a day-to-day basis the border crossings between home and school.

A significant limitation of this review is that only English language publications have been included. Many values researchers are active throughout Asia, and publications in various languages exist. A recent study by Peng and Nyroos (2012) published in Korean in The Mathematical Education journal of the Korean Society for Mathematics Education is one such example.

\section{Appendix: Summary of Studies}




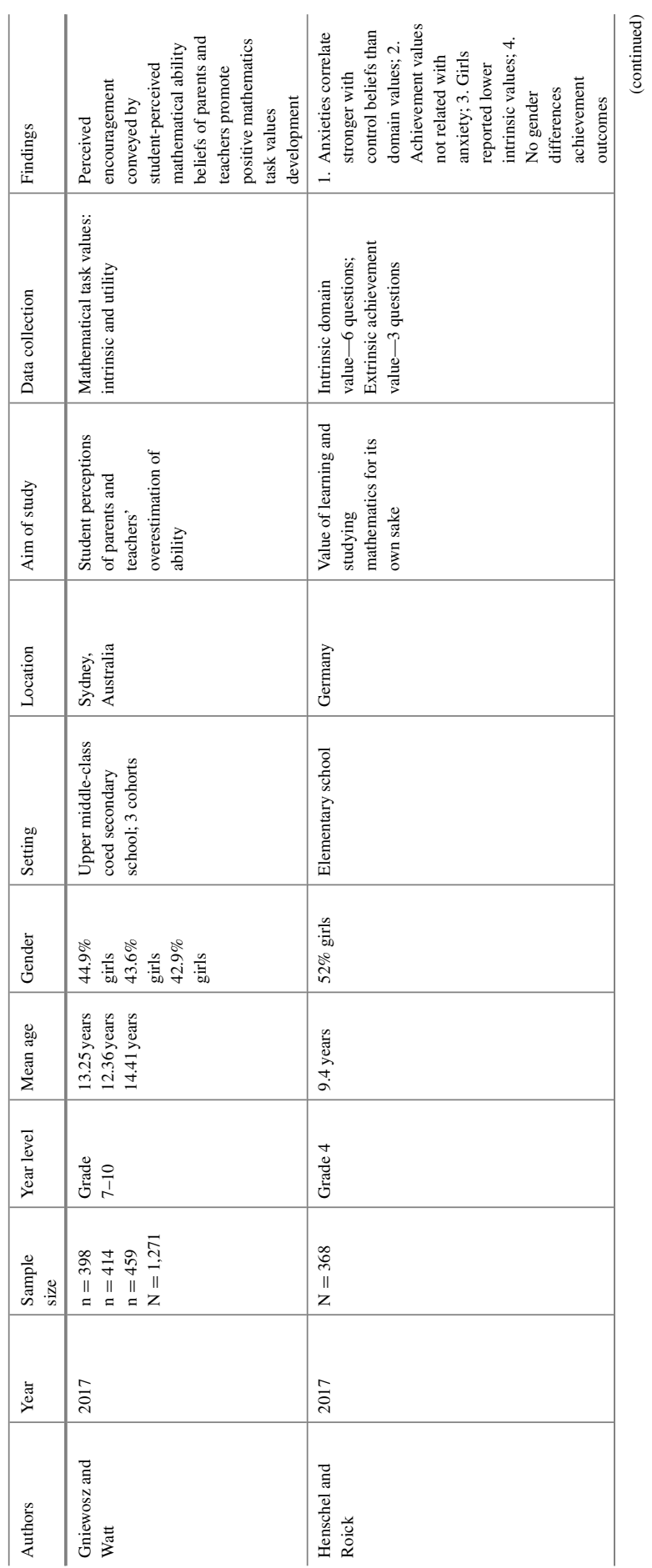




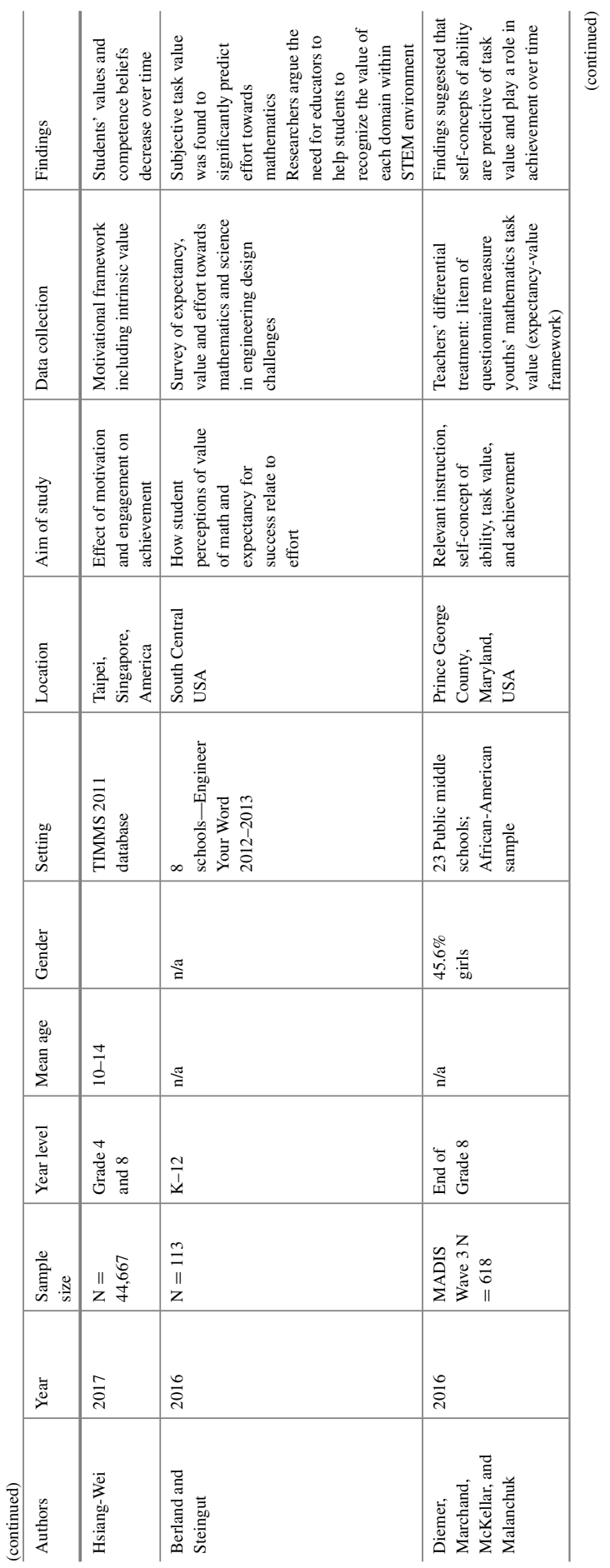




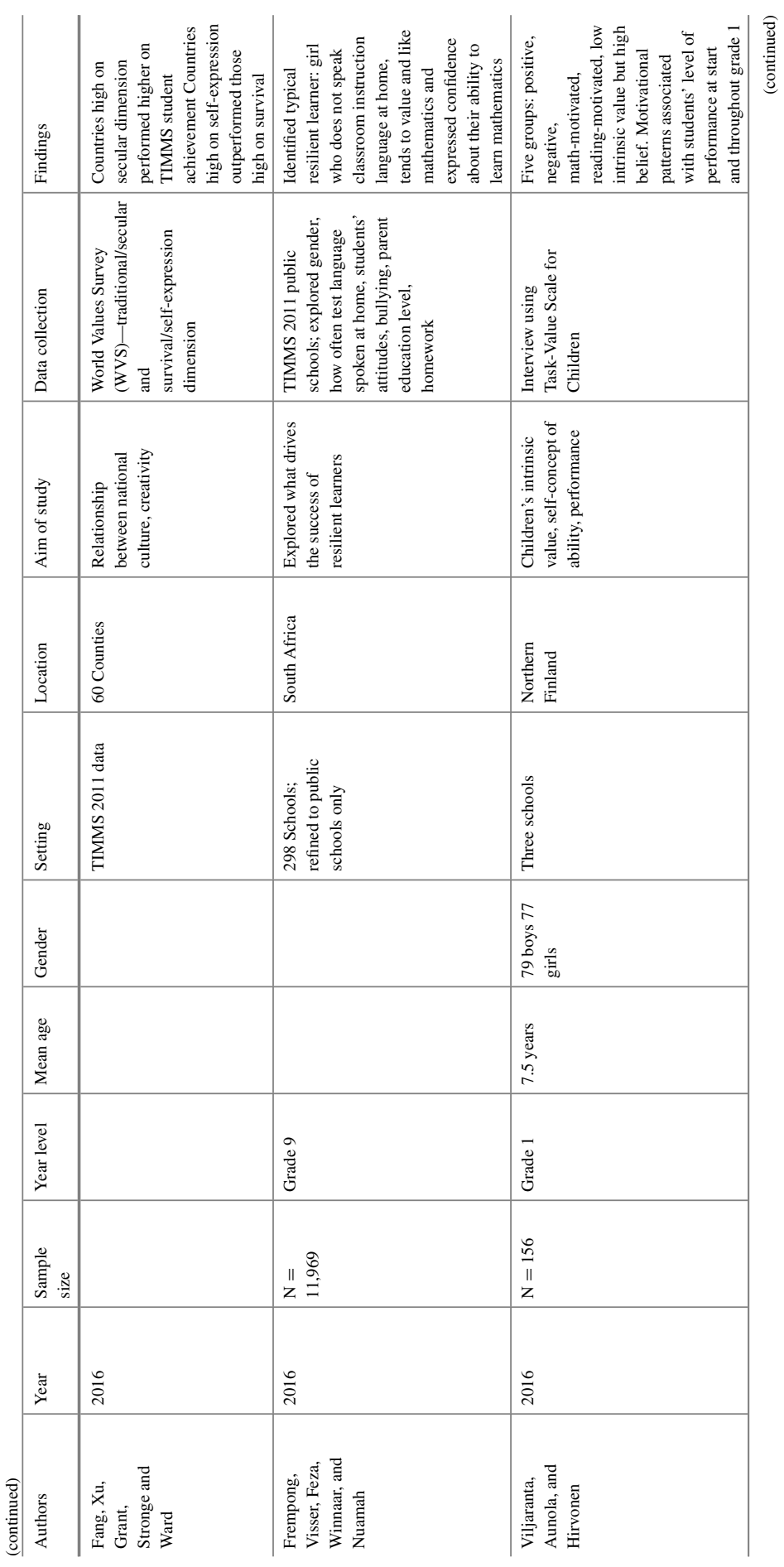




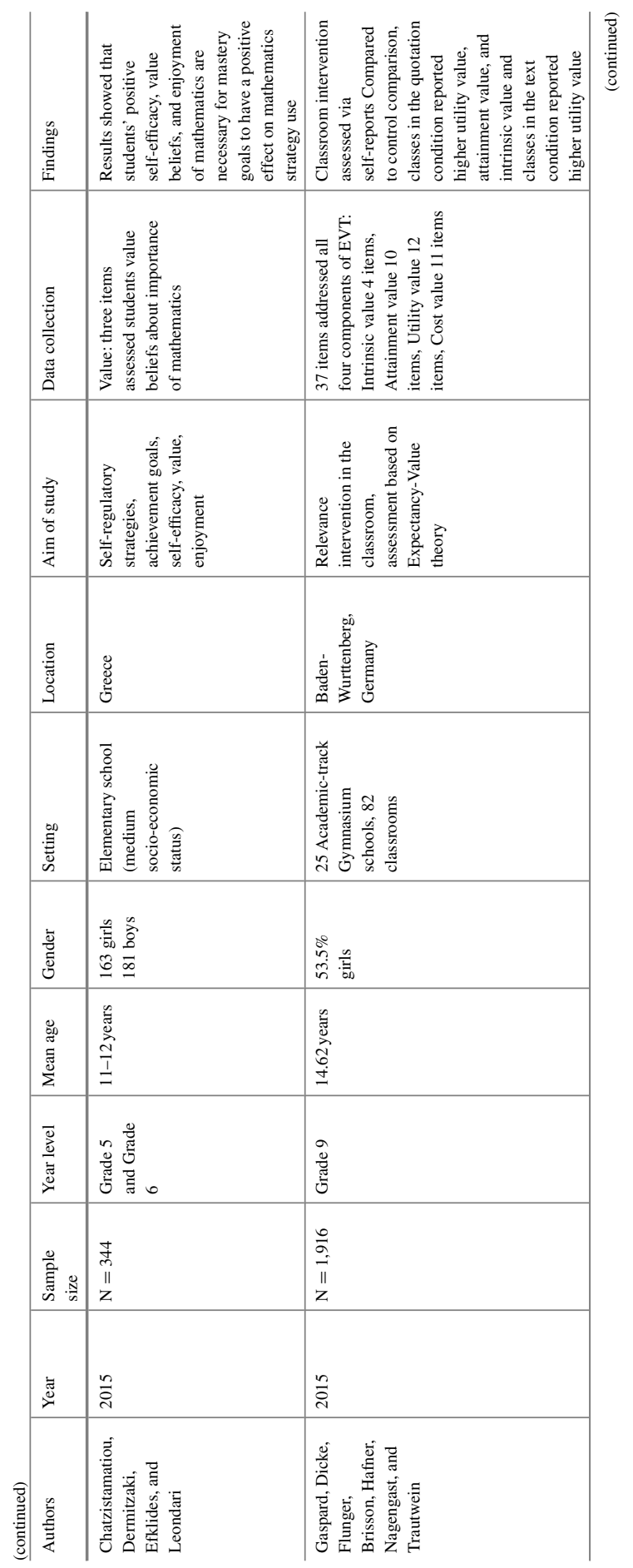




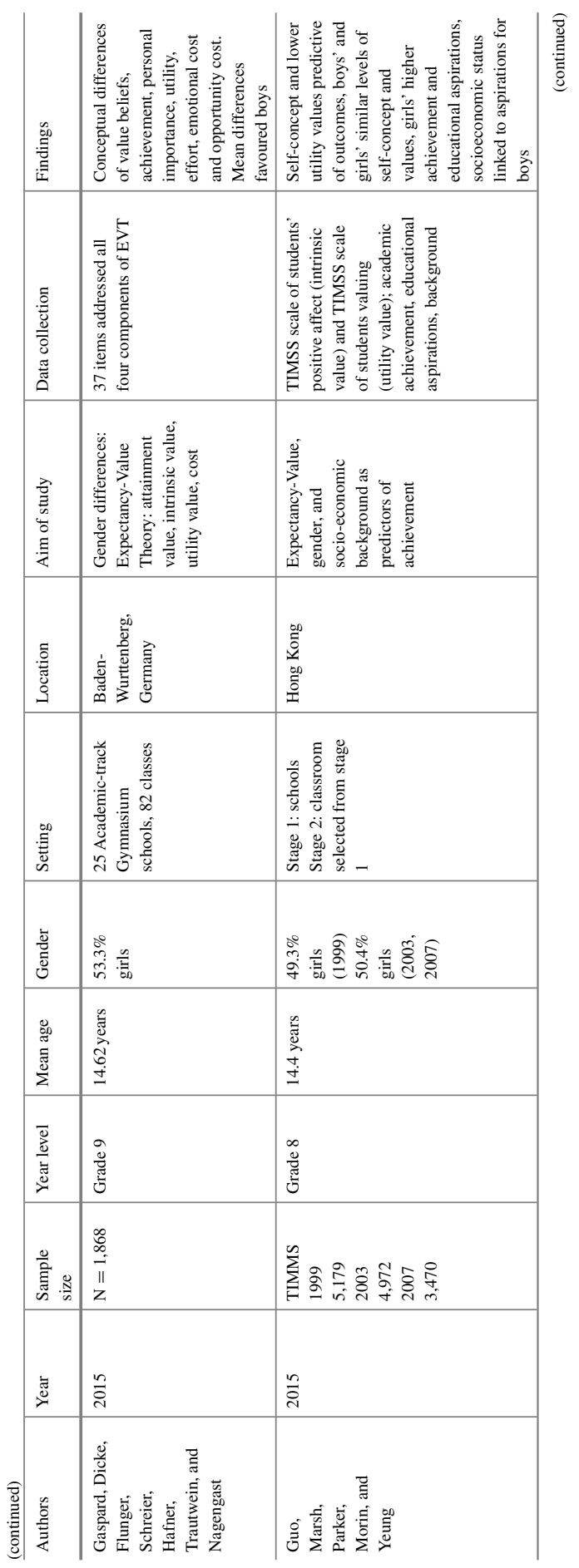




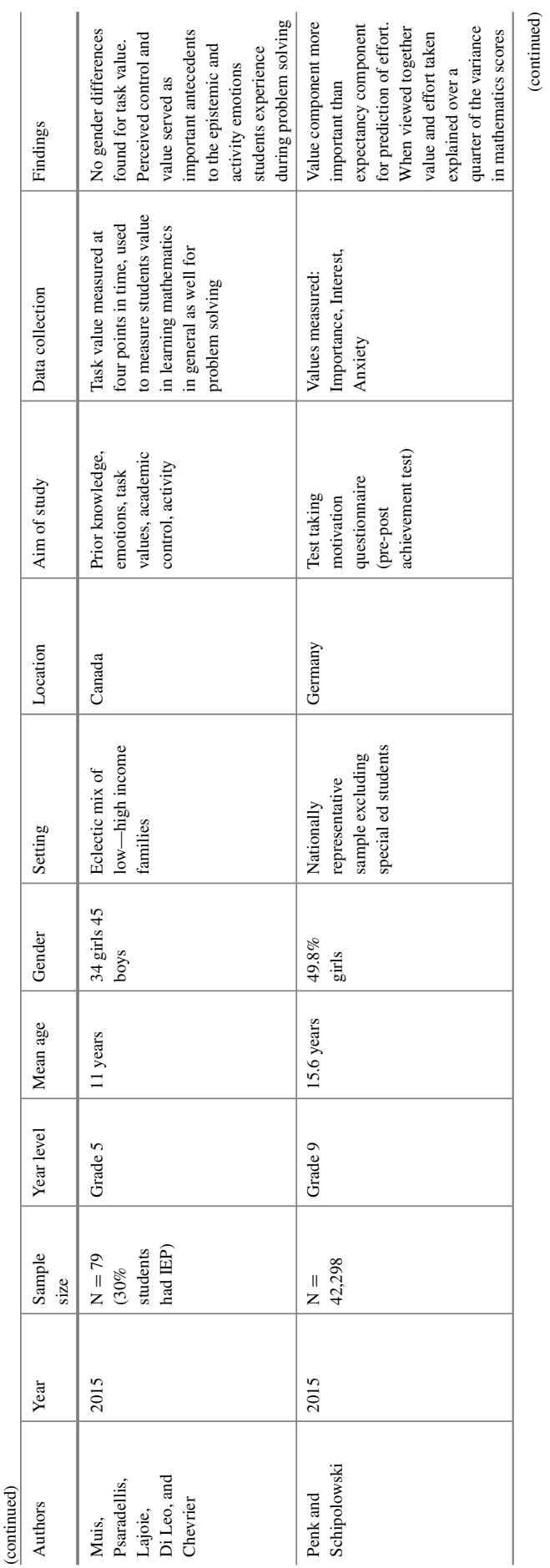




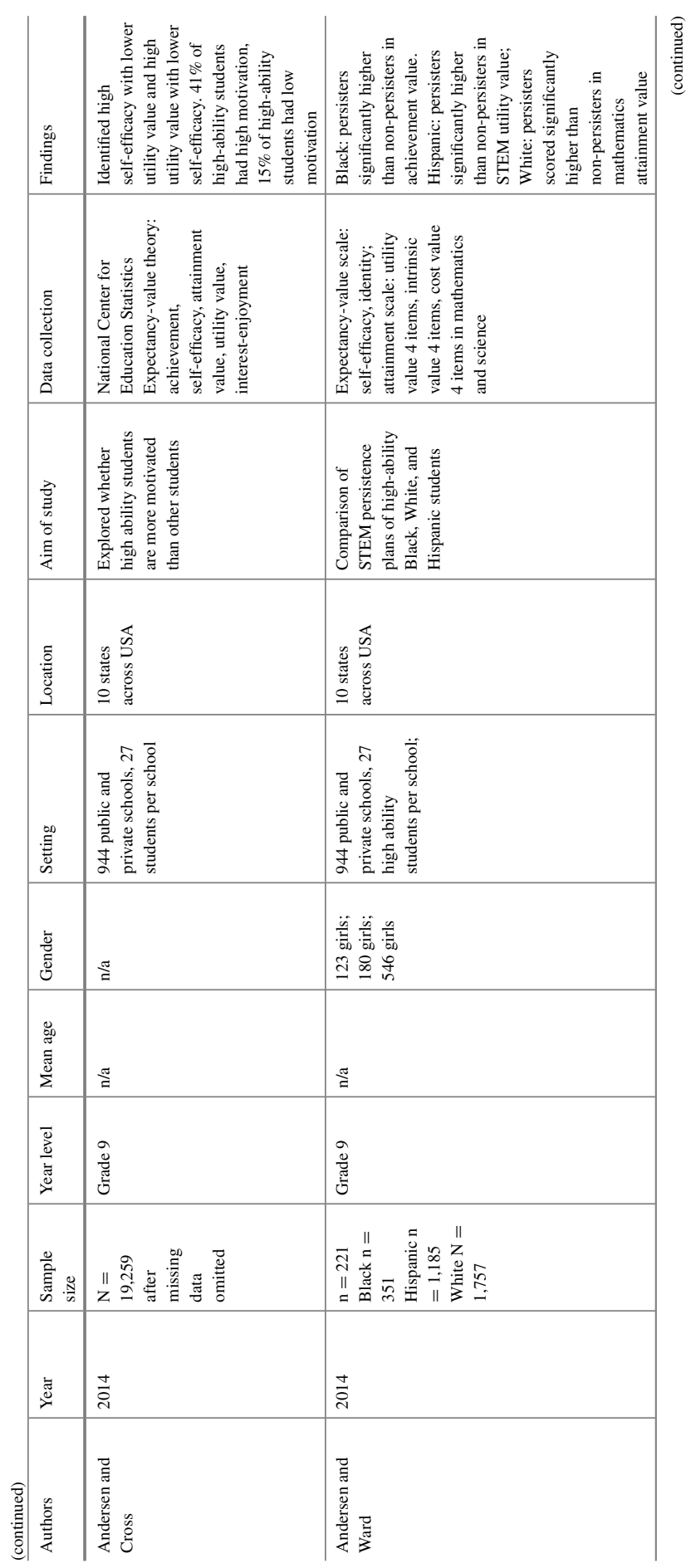




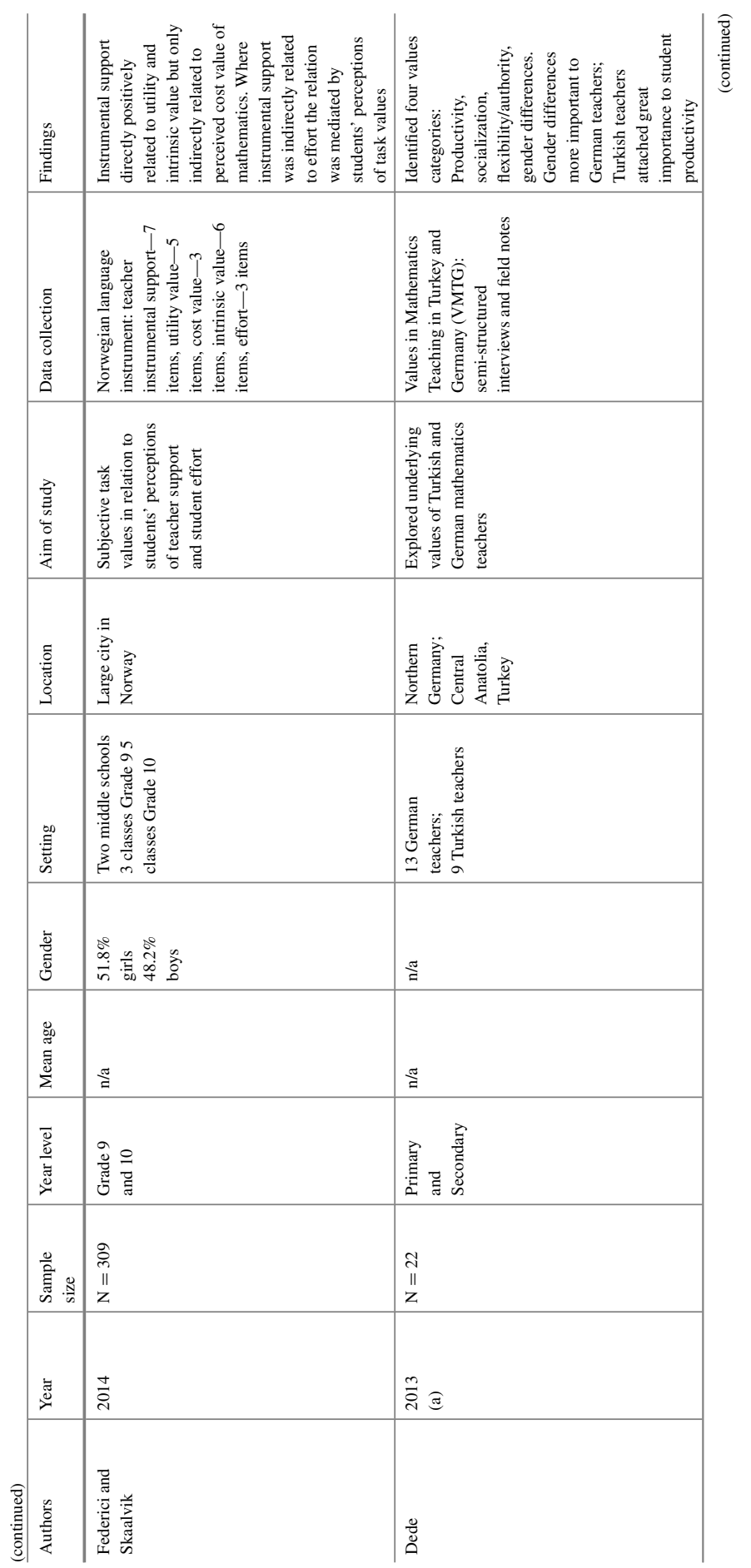




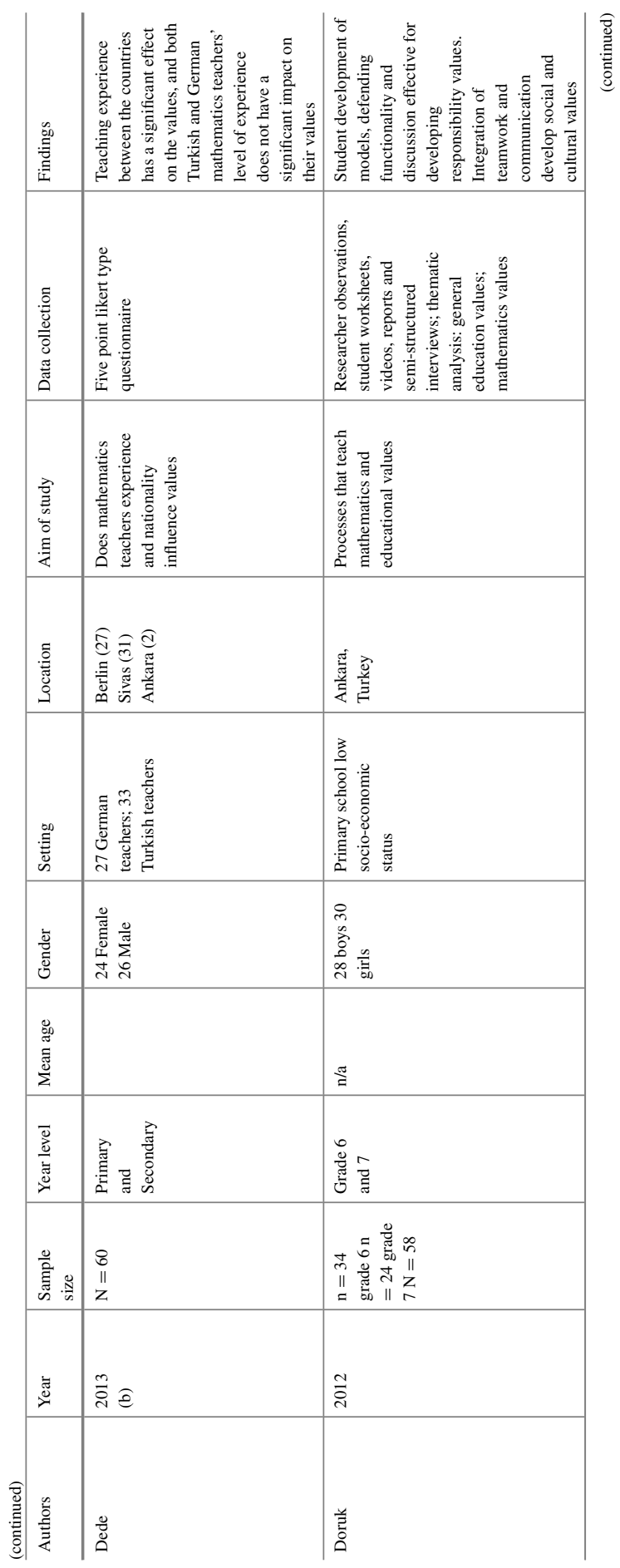




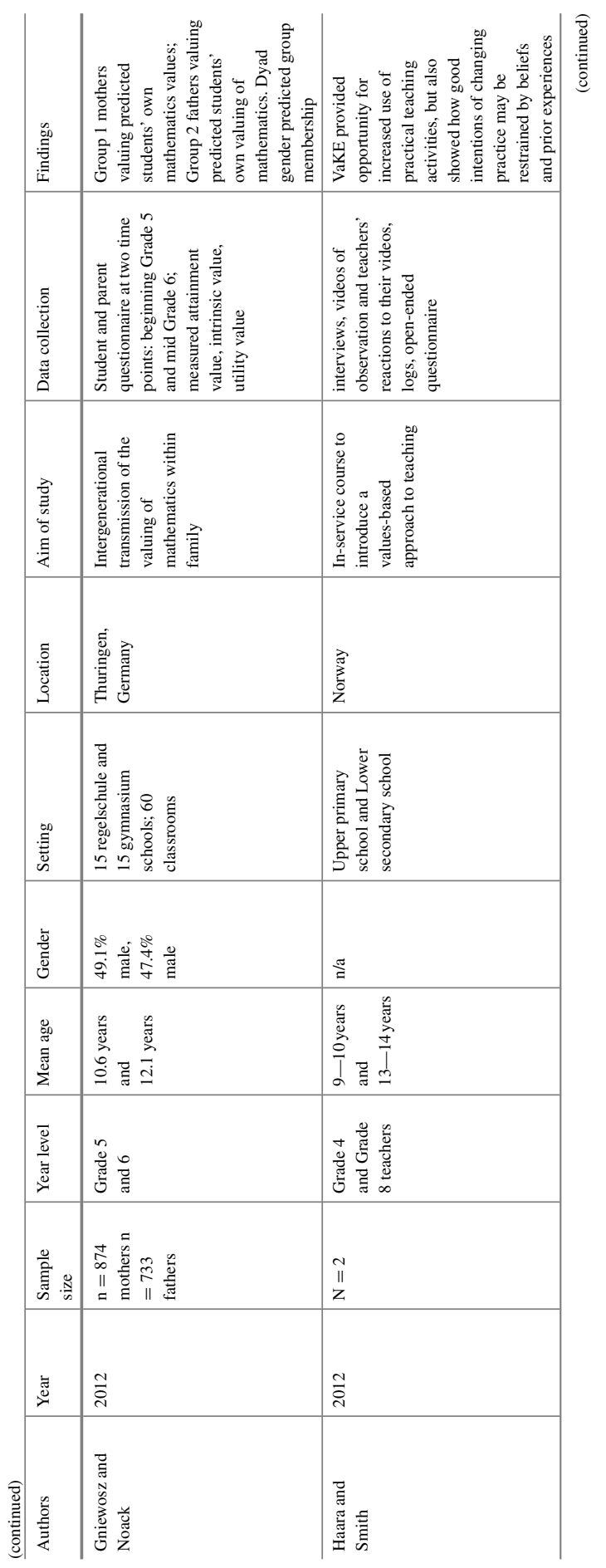




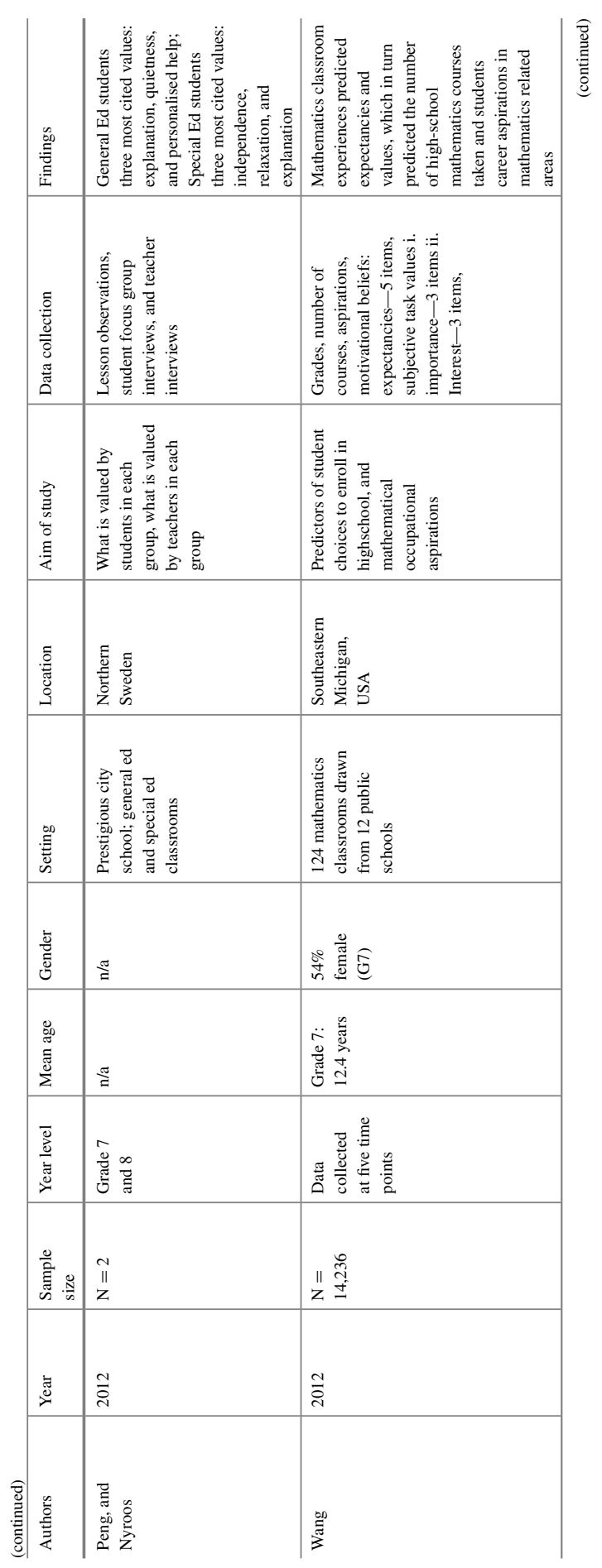




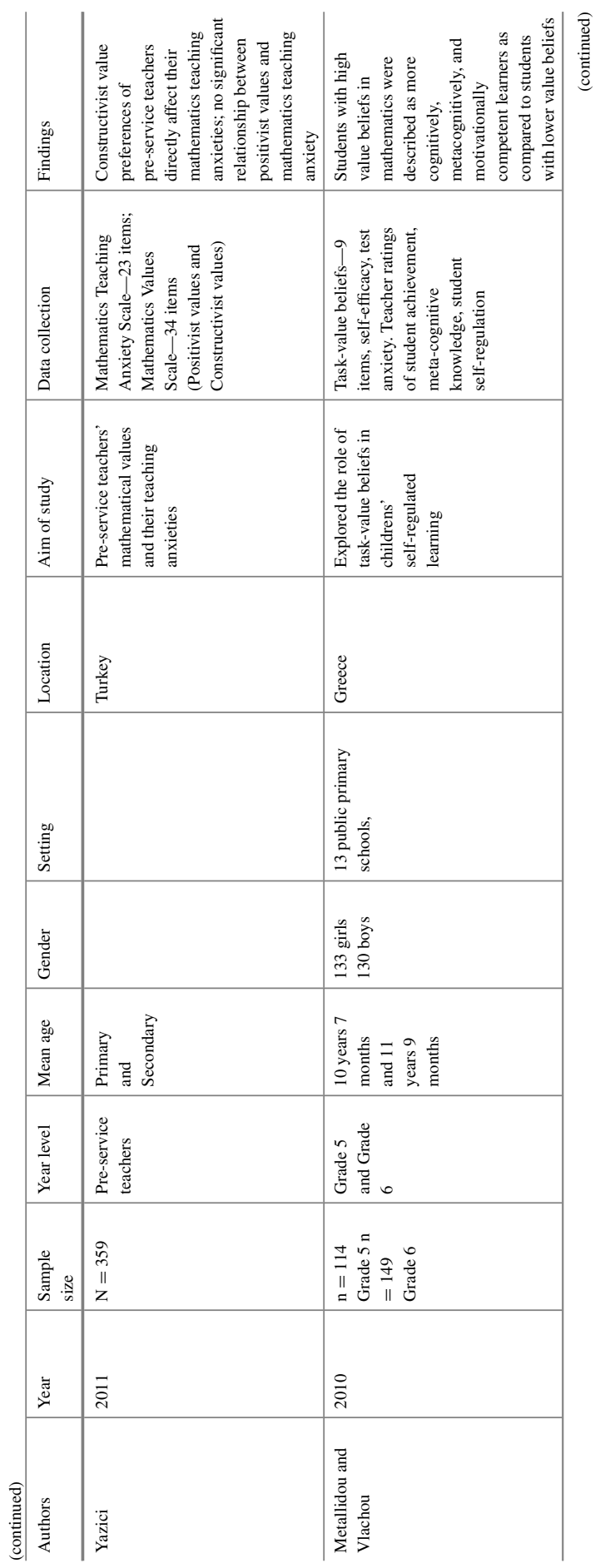




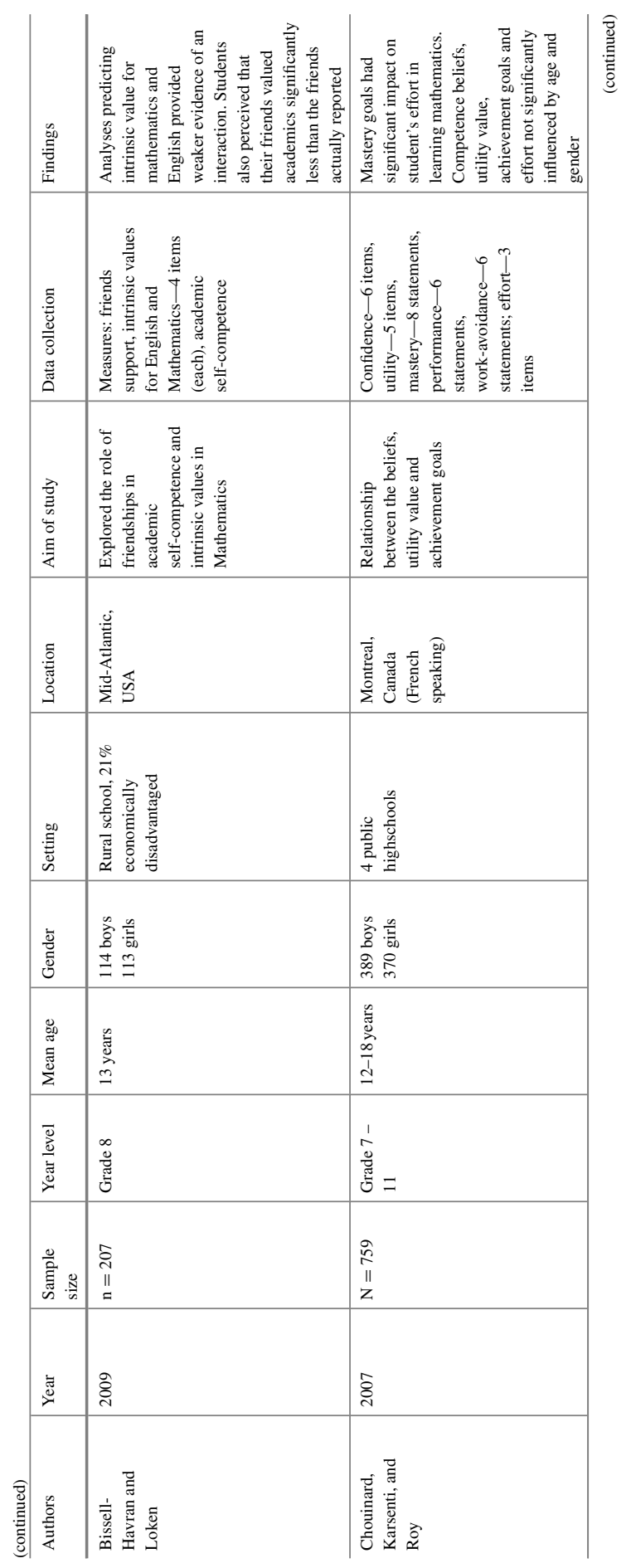




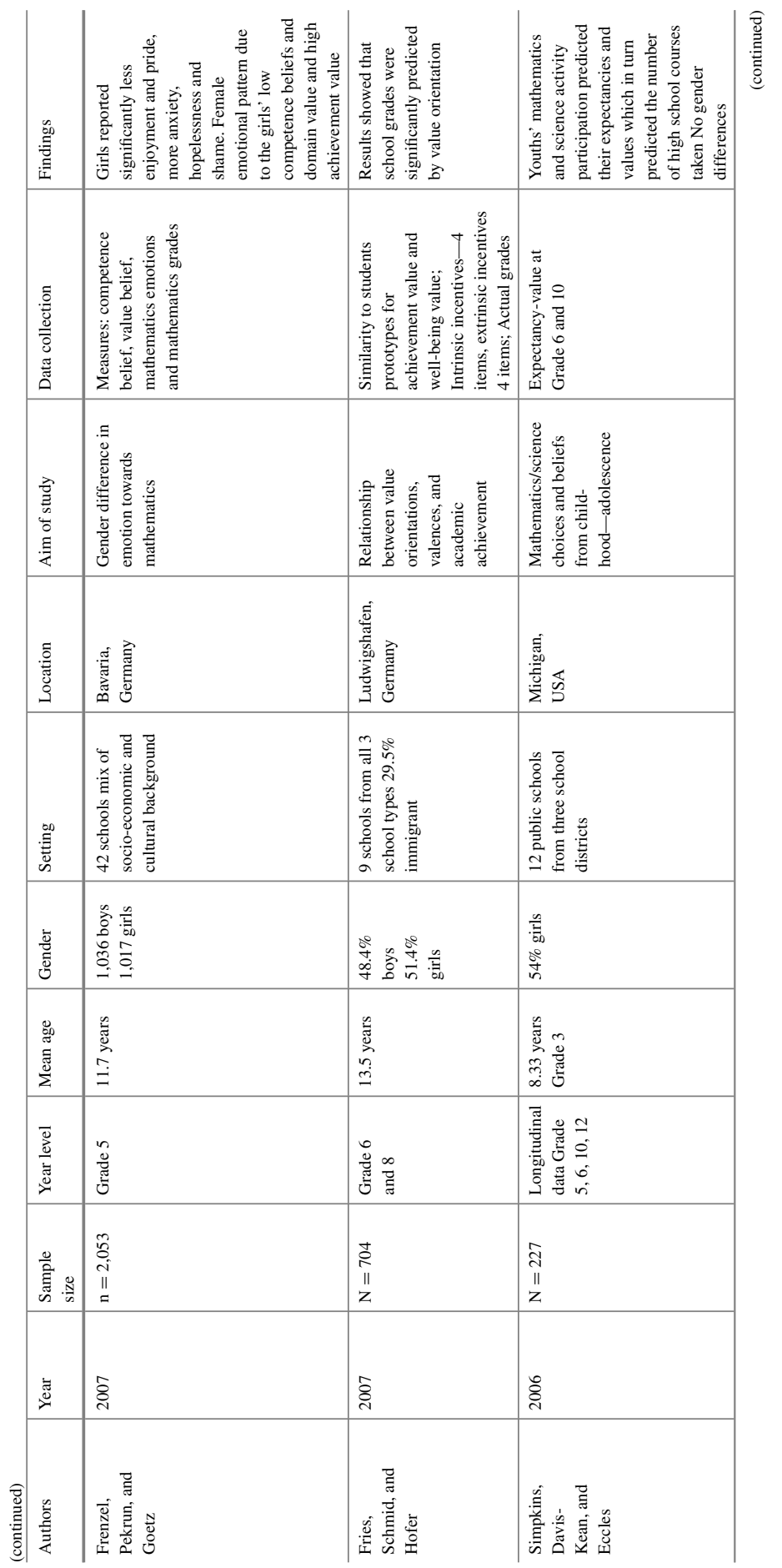




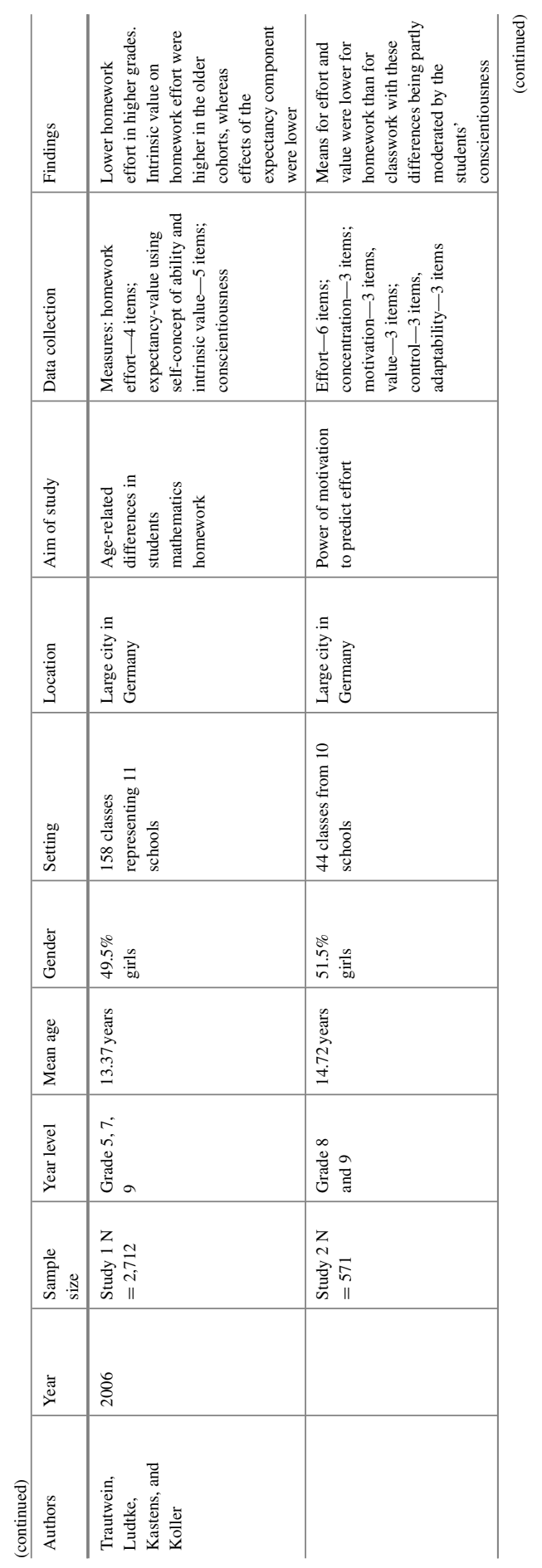




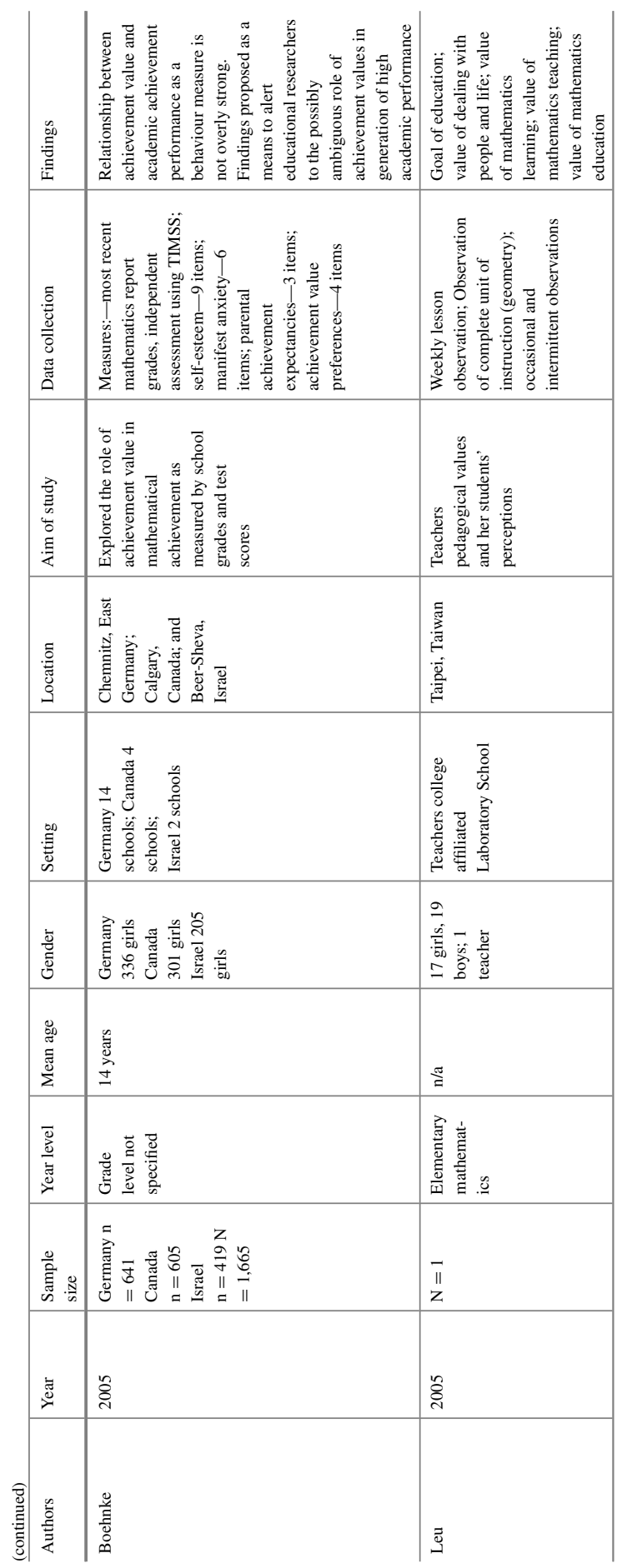




\section{References}

*References marked with an asterisk indicate studies identified in the systematic literature review.

*Andersen, L., \& Cross, T. L. (2014). Are students with high ability in math more motivated in math and science than other students? Roeper Review: A Journal on Gifted Education, 36(4), 221-234.

*Andersen, L., \& Ward, T. J. (2014). Expectancy-value models for the STEM persistence plans of ninth-grade, high-ability students: A comparison between Black, Hispanic, and White students. Science Education, 98(2), 216-242.

*Berland, L. K., \& Steingut, R. (2016). Explaining variation in student efforts towards using math and science knowledge in engineering contexts. International Journal of Science Education, 38(18), 2742-2761. https://doi.org/10.1080/09500693.2016.1260179.

Bishop, A. (1988a). Mathematics education in its cultural context. Educational Studies in Mathematics, 19(2), 179-191.

Bishop, A. (1988b). Mathematical encultration: A cultural perspective on mathematics education. Dordrecht, Netherlands: Kluwer.

Bishop, A. J., Seah, W. T., \& Chin, C. (2003). Values in mathematics teaching: The hidden persuaders? In A. J. Bishop, K. Clements, C. Keitel, J. Kilpatrick, \& F. Leong (Eds.), International handbook of mathematics education (2nd ed., pp. 715-763). Dordrecht, The Netherlands: Kluwer Academic Publishers.

*Bissell-Havran, J. M., \& Loken, E. (2009). The role of friends in early adolescents' academic self-competence and intrinsic value for math and English. Journal of Youth and Adolescence, $38(1), 41-50$.

*Boehnke, K. (2005). Value orientations in relation to mathematical self-esteem: An exploratory study of their role in mathematical achievement among German, Israeli, and Canadian 14-yearolds. European Journal of Psychology of Education, 20(3), 227-241.

*Chatzistamatiou, M., Dermitzaki, I., Efklides, A., \& Leondari, A. (2015). Motivational and affective determinants of self-regulatory strategy use in elementary school mathematics. Educational Psychology, 35(7), 835-850.

*Chouinard, R., Karsenti, T., \& Roy, N. (2007). Relations among competence beliefs, utility value, achievement goals, and effort in mathematics. British Journal of Educational Psychology, 77(3), 501-517.

Dede, Y. (2006). Values in Turkish middle school mathematics textbooks. Quality \& Quantity, 40, 331-359.

*Dede, Y. (2013a). Examining the underlying values of Turkish and German mathematics teachers decision making processes in group studies. Educational Science Theory \& Practice, 13(1), 690-706.

*Dede, Y. (2013b). The effect of German and Turkish mathematics teachers' teaching experience on mathematics education values: A cross-comparative study. International Journal of Mathematics Education in Science and Technology, 44(2), 232-252. https://doi.org/10.1080/0020739x.2012. 714489.

*Diemer, M. A., Marchand, A. D., McKellar, S. E., \& Malanchuk, O. (2016). Promotive and corrosive factors in African American students' math beliefs and achievement. Journal of Youth and Adolescence, 45(6), 1208-1225.

*Doruk, B. K. (2012). Mathematical modeling activities as a useful tool for values education. Kuram ve Uygulamada Egitim Bilimleri. 12(2, Suppl), 1667-1672.

Eklof, H. (2007). Self-concept and valuing of mathematics in TIMSS 2003: Scale structure and relation to performance in a Swedish setting. Scandinavian Journal of Educational Research, 51(3), 297-313.

*Fang, Z., Xu, X., Grant, L. W., Stronge, J. H., \& Ward, T. J. (2016). National culture, creativity, and productivity: What's the relationship with student achievement? Creativity Research Journal, 28(4), 395-406. https://doi.org/10.1080/10400419.2016.1229976. 
*Federici, R. A., \& Skaalvik, E. M. (2014). Students' perception of instrumental support and effort in mathematics: The mediating role of subjective task values. Social Psychology of Education, $17(3), 527-540$.

*Frempong, G., Visser, M., Feza, N., Winnar, L., \& Nuamah, S. (2016). Resilient learners in schools serving poor communities. Electronic Journal of Research in Educational Psychology, 14(2), 352-367. https://doi.org/10.14204/ejrep.39.15038.

*Frenzel, A. C., Pekrun, R., \& Goetz, T. (2007). Girls and mathematics-A "hopeless" issue? A control-value approach to gender differences in emotions towards mathematics. European Journal of Psychology of Education, 22(4), 497-514.

*Fries, S., Schmid, S., \& Hofer, M. (2007). On the relationship between value orientation, valences, and academic achievement. European Journal of Psychology of Education, 22(2), 201-216.

Furuto, L. (2014). Pacific ethnomathematics: Pedagogy and practices in mathematics education. Teaching Mathematics and its Applications, 33(2), 110-121.

*Gaspard, H., Dicke, A., Flunger, B., Brisson, B. M., Hafner, I., Nagengast, B., et al. (2015a). Fostering adolescents' value beliefs for mathematics with a relevance intervention in the classroom. Developmental Psychology, 51(9), 1226-1240.

*Gaspard, H., Dicke, A., Flunger, B., Schreier, B., Hafner, I., Trautwein, U., et al. (2015b). More value through greater differentiation: Gender differences in value beliefs about math. Journal of Educational Psychology, 107(3), 663-677.

*Gniewosz, B., \& Watt, H. M. (2017). Adolescent-perceived parent and teacher overestimation of mathematics ability: Developmental implications for students' mathematics task values. Developmental Psychology, 53(7), 1371-1383.

*Gniewosz, B., \& Noack, P. (2012). Mamakind or papakind? [Mom's child or Dad's child]: Parentspecific patterns in early adolescents' intergenerational academic value transmission. Learning and Individual Differences, 22(4), 544-548.

*Guo, J., Marsh, H. W., Parker, P. D., Morin, A. J. S., \& Yeung, A. S. (2015). Expectancy-value in mathematics, gender and socioeconomic background as predictors of achievement and aspirations: A multi-cohort study. Learning and Individual Differences, 37, 161-168.

*Haara, F. O., \& Smith, K. (2012). Increasing the use of practical activities through changed practice. The Mathematics Enthusiast, 9(1-2), 77-110.

*Henschel, S., \& Roick, T. (2017). Relationships of mathematics performance, control and value beliefs with cognitive and affective math anxiety. Learning and Individual Differences, 55, 97-107.

*Hsiang-Wei, K. (2017). The effects of motivational constructs and engagement on mathematics achievements; A comparative study using TIMSS 2011 data of Chinese Taipei, Singapore and the USA. Asia Pacific Journal of Education, 37(2), 135-149. https://doi.org/10.1080/02188791. 2016.121682.

Kluckhohn, F. R., \& Strodbeck, F. L. (1961). Variations in value orientations. Westport: CT, Greenwood Press.

Leu, Y. C. (2005). The encactment and perceptions of mathematics pedagogical values in an elementary classroom: Buddhism, Confucianism, and curriculum reform. International Journal of Science and Mathematics Education, 3, 175-212.

*Metallidou, P., \& Vlachou, A. (2010). Children's self-regulated learning profile in language and mathematics: The role of task value beliefs. Psychology in the Schools, 47(8), 776-788.

*Muis, K. R., Psaradellis, C., Lajoie, S. P., Di Leo, I., \& Chevrier, M. (2015). The role of epistemic emotions in mathematics problem solving. Contemporary Educational Psychology, 42, 172-185.

Parsons, T., \& Shils, E. A. (1951). Toward a generall theory of action. Cambridge: MA, Harvard University Press.

*Peng, A., \& Nyroos, M. (2012). Values in effective mathematics lessons in Sweden: What do they tell us? The Mathematics Enthusiast, 9(3), 409-430.

*Penk, C., \& Schipolowski, S. (2015). Is it all about value? Bringing back the expectancy component to the assessment of test-taking motivation. Learning and Individual Differences, 42, 27-35. 
Seah, W. T. (2018). Improving mathematics pedagogy through student/teacher valuing: Lessons from five continents. In G. Kaiser, H. Forgasz, M. Graven, A. Kuzniak, E. Simmt, \& B. Xu (Eds.), Invited Lectures from the 13th International Congress on Mathematical Education (pp. 561-580). Switzerland, Springer: Cham.

Seah, W. T., \& Andersson, (2015). Valuing diversity in mathematics pedagogy through the volitional nature and alignment of values. In A. Bishop, H. Tan, \& T. Barkatas (Eds). Diversity in mathematics education: Towards inclusive practices (pp. 167-183). Switzerland: Springer

Seah, W. T., \& Bishop, A. (2001) Teaching more than numeracy: The socialisation experience of a migrant teacher. In 1. Bobis, B. Perry \& M, Mitchelmore (Eds.), Numeracy and beyond: Proceedingsof the Twenty-Fourth Annual Conference of the Mathematics Education Research Group of Australasia (Vol. 2, pp. 442-450). Turramurra, Australia: Mathematics Education Research Group of Australasia.

*Simpkins, S. D., Davis-Kean, P. E., \& Eccles, J. S. (2006). Math and science motivation: A longitudinal examination of the links between choices and beliefs. Developmental Psychology, 42(1), 70-83.

Timms, M., Moyle, K., Weldon, P., \& Mitchell, P. (2018). Challenges in STEM learning in Australian schools. Australian Council for Education Research: Literature and Policy Review.

*Trautwein, U., Lüdtke, O., Kastens, C., \& Köller, O. (2006). Effort on homework in grades 5-9: Development, motivational antecedents, and the association with effort on classwork. Child Development, 77(4), 1094-1111.

*Viljaranta, J., Aunola, K., \& Hirvonen, R. (2016). Motivation and academic performance among first-graders: A person-oriented approach. Learning and Individual Differences., 49, 366-372.

*Wang, M. (2012). Educational and career interests in math: A longitudinal examination of the links between classroom environment, motivational beliefs, and interests. Developmental Psychology, 48(6), 1643-1657.

*Yazici, E., Peker, M., Ertekin, E., \& Dilmac, B. (2011). Is there a relationship between pre-service teachers' mathematical values and their teaching anxieties in mathematics? Electronic Journal of Research in Educational Psychology, 9(1), 263-282.

Open Access This chapter is licensed under the terms of the Creative Commons Attribution 4.0 International License (http://creativecommons.org/licenses/by/4.0/), which permits use, sharing, adaptation, distribution and reproduction in any medium or format, as long as you give appropriate credit to the original author(s) and the source, provide a link to the Creative Commons license and indicate if changes were made.

The images or other third party material in this chapter are included in the chapter's Creative Commons license, unless indicated otherwise in a credit line to the material. If material is not included in the chapter's Creative Commons license and your intended use is not permitted by statutory regulation or exceeds the permitted use, you will need to obtain permission directly from the copyright holder.

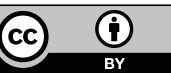

